\title{
The meaning and measurement of customer retention
}

Received: 7th February, 20001

\author{
Edward Aspinall \\ is Head of Relationship Markets, Royal Mail.
}

\section{Clive Nancarrow}

is Professor in Marketing at Bristol Business School, UWE.

\section{Merlin Stone}

is IBM Professor of Relationship Marketing, Bristol Business School, UWE, Executive Consultant IBM Business Innovation Services, and a Director of QCi Ltd. and Swallow Information Systems Ltd.

\begin{abstract}
Retaining good customers (or those that may become good) is one of the most important topics in customer relationship marketing (CRM). ${ }^{1}$ Its importance is not confined to CRM - customer retention has a pedigree that goes back to the era of classic direct marketing and branding. But how professionally do companies approach this topic?

The research described in this paper was commissioned by the Royal Mail as part of a programme aimed at identifying the role of mail in keeping customers. This first report on the research focuses on conceptual and definitional issues.
\end{abstract}

\section{THE MEANING OF CUSTOMER RETENTION IN A DATABASE ENVIRONMENT}

Success in business is dependent on clear thinking on the fundamental conceptual issues. If customer retention is a major focus, then a key question is what exactly is an organisation trying to retain? The list of possibilities is long (see Table 1). Behavioural definitions (such as those listed below) may seem more relevant in some respects but in other respects may blind marketers to underlying weaknesses in the customer franchise or disposition. Apathy may lead some customers to demonstrate apparent 'loyalty' or 'commitment' based on behavioural measures. Other customers may resent buying from an organisation but be locked into the supplier for various reasons. In such cases, the reason for staying 'loyal' or 'committed' is that the emotional and financial cost of changing supplier at that point in time is too great to countenance. If, however, a competitor identifies this weakness and makes it not just easy but rewarding for a customer to switch then apparently loyal customers may do so in droves. There are also customers who do not buy but feel some 'loyalty'! Barriers (price, access etc.) may prevent a purchase. Once the barriers are removed, however, the loyal customer can demonstrate loyalty or commitment in behavioural terms.

Changes in attitudes are more often than not antecedents of changes in behaviour in all but very low involvement product categories. So while 
Table 1: The multifaceted nature of retention: some examples

\begin{tabular}{ll}
\hline Behaviour & Hearts and minds (attitudinal variables) \\
\hline $\begin{array}{l}\text { Number of customers (including dormant) } \\
\text { Number of active customers }\end{array}$ & $\begin{array}{l}\text { Salience of brand proposition and its components } \\
\text { Brequency of buying }\end{array}$ \\
$\begin{array}{l}\text { Psychological commitment/loyalty (eg NFO/BJM }{ }^{2} \text { and } \\
\text { Recency of buying }\end{array}$ & $\begin{array}{c}\text { Millward Brown models } \\
\text { Size of expenditure }\end{array}$ \\
Share of expenditure & Empathy \\
Possibly even extent of cross-sales & Propensity to consider buying/use again/contribute \\
Contract & resources \\
Adjust buying/usage procedures to fit supplier & Propensity to pay more/a premium (eg Rl's equity \\
Routinised re-ordering & engine/model) \\
Join club & Customer satisfaction/delight \\
Proven advocacy & Likelihood to recommend/advocacy \\
Enquiries & Possibly even top-of-the mind awareness \\
Provide information when requested & \\
re needs and/or characteristics & \\
Notify of complaints and successes & \\
Give you more time than competitors/before & \\
Pay attention to organisation's announcements & \\
\hline
\end{tabular}

behaviour in various forms of purchasing activity understandably attracts the attention of many hard-nosed marketers seeking hard evidence of retention, the value of the attitudinal variables (soft evidence) should not be underestimated. Behaviour is a reflection of the current or more likely historical situation, while attitudes provide clues to future behaviour. In a perfect world, one would examine both behavioural and attitudinal variables and at the same time examine the relationships to determine what drives behavioural disposition. A number of marketing research models attempt to do this, for example, RI's Equity Engine and the NFO/BJM Brand Equity Model, ,,5 both link brand attribute ratings to behavioural disposition rather than behaviour itself. It should also be noted that the link between the psychological and behavioural is sometimes far from perfect as has been noted in terms of customer satisfaction and behavioural measures of retention or loyalty. ${ }^{6}$ In an ideal world, management would develop a customer behaviour model that incorporates all the relevant key variables and describes the relationship between them. The model may be a simple qualitative description of how the variables influence each other. In some organisations it might be possible to develop sophisticated statistical algorithms that permit 'what if' analyses.

Thus from a conceptual and operational viewpoint, it may be that no single variable should be regarded as representing 'retention'. Any one variable may have shortcomings as a measure of commitment or brand strength.

\section{THE CONCEPT OF LOYALTY}

Before moving on to the measurement of retention, it is necessary to address very briefly the concept of loyalty. References to brand 'loyalty' can be found in the early years of marketing. ${ }^{7}$ The concept of loyalty (allegiance to monarchy, causes and people) fits in with the military terms found in marketing (strategy, targeting, etc.). Interestingly, loyalty is subordinate within the concept of a relationship, yet brand loyalty was a term commonly used in marketing before the wide adoption of the principle of relationship marketing. This would suggest in early marketing circles at least the term may not have had the full 
metaphorical significance of loyalty as in an interpersonal relationship. It may instead have been interpreted as a positive disposition to a brand that transcends transactions and makes repurchase likely in the face of adversity (competitor brand entreaties). On occasions the power of such entreaties from competitors may prove too much and disloyal behaviour may be exhibited. It is, however, possible no unpleasant feelings of disloyalty are experienced as might be the case of an interpersonal relationship. Of course, in some intense service categories such feelings may be manifest (for example, local shops, post offices and service providers, hairdressers, restaurants, football clubs and friendly financial services advisers). Purchasing of foreign goods may also evoke feelings of disloyalty and guilt.

Assuming, therefore, that some form of behavioural or attitudinal mark of allegiance is sought, but perhaps without the finer points of loyalty exhibited in its classical settings, then many of the variables listed as relevant to customer retention would also be potential manifestations of loyalty. It is quite likely that adopting one criterion for (or measure of) loyalty (or retention) may not be perfectly valid. Many organisations should certainly try and narrow down a small set of criteria that seem to account for all or most aspects of the phenomenon but look at these in the round. Dependence on one criterion may be misleading in some instances. This may explain why the same customer was defined as 'loyal' in one study and 'not loyal' in another. ${ }^{8}$ Therefore, composite measures of retention may be a more sensible approach. For instance, Stratigos recommends three indices: ${ }^{9}$

- likelihood to use and renew

- likelihood to contribute
Table 2: Framework for loyalty classification

\begin{tabular}{|c|c|c|c|}
\hline & & $\begin{array}{l}\text { Behav } \\
\text { Low }\end{array}$ & $\begin{array}{l}\text { I loyalty } \\
\text { High }\end{array}$ \\
\hline $\begin{array}{l}\text { Attitudinal } \\
\text { loyalty }\end{array}$ & $\begin{array}{l}\text { High } \\
\text { Low }\end{array}$ & $\begin{array}{l}\text { Latent } \\
\text { Low }\end{array}$ & $\begin{array}{l}\text { High } \\
\text { Spurious }\end{array}$ \\
\hline
\end{tabular}

— likelihood to recommend.

It has been argued that real purchase behaviour and advocacy are appropriate in some categories. ${ }^{10}$ A number of authors clearly define loyalty as a two dimensional construct - behavioural and attitudinal - and on this basis Liddy developed a potentially useful two by two matrix for loyalty classification, as shown in Table $2 .{ }^{11}$

Classifying and counting the number of customers in each quadrant in the table might be very illuminating in terms of opportunities and vulnerabilities. The matrix may, however, suggest loyalty is binary when in reality there may be several different categories of loyalty (exclusively buy from one supplier; preferred brand among several; one of many regularly buy but not preferred etc.).

It is self-evident that retention criteria and their measures will differ in relevance and importance from product category to category. Finding the best definition and measures is clearly vital to how well an organisation can evaluate its performance and link this performance to actions in the market.

While much has been written about customer retention definition and measurement, there has not been an extensive survey of UK organisations to establish the extent to which various definitions and measures are in use. In addition, if customer retention is measured it is not clear how retention levels are evaluated (benchmarks used) nor the extent of research related to understanding what drives customer 
retention. A study by KPMG suggested that such research is not always shared within an organisation. ${ }^{12}$ It would be useful to know the extent to which senior management, in particular, monitor customer retention. The customer management scorecard report ${ }^{13}$ indicates that many organisations do not fully implement a customer retention strategy, by virtue of weaknesses in preventing attrition by not using customer information, for instance, to alert customer facing staff of potential problems. It would be interesting to determine the extent to which customer information relevant to retention is collected and, more importantly, used. Finally, it has been argued that cross-selling can build loyalty and retain customers. ${ }^{14}$ The extent of this belief among practitioners is not clear, however. Nor is it clear whether there is hard evidence to support the proposition.

\section{THE RESEARCH PROGRAMME}

\section{The aim and research objectives}

The primary aim of the research is to identify where weaknesses in customer information, in particular definitions and measures of retention and the use of the information, are most likely to undermine customer retention strategies.

The main objectives of the research exercise were to:

- assess the relative emphasis on customer acquisition and customer retention across business sectors and so focus on organisations that are retention oriented

- determine the extent to which organisations have agreed clear definitions of what constitutes customer retention

- determine how customer retention is measured
- determine benchmarks used to help interpret customer retention measures

- determine how well organisations use customer retention information

- determine what other customer information is used

- determine the extent of the belief that cross-selling builds loyalty/helps retain customers and the evidence for this.

\section{Method}

Using a centralised telephone interviewing facility, 314 telephone interviews were conducted with employees at managerial/director level who were responsible for the marketing from a customer database(s) within their organisation. The fieldwork was conducted by BJM Research \& Consultancy, part of the NFO Worldwide group of companies.

The business sectors that were included were selected on the basis that they were more likely to be involved in customer management of some description and that they were likely to have databases of at least 400 customers. In addition, quotas were imposed on larger companies to ensure that a sufficient number of those with 250 or more employees were interviewed. Twenty-four mail order and 24 dot.com companies were also included for analysis. The reader should bear in mind the low sample sizes for these companies when examining the findings.

Interviewing was conducted between 8th and 28th September 2000. Interviewers were briefed in person by Professor Clive Nancarrow (Bristol Business School, UWE) and Claire Sharman (BJM).

In addition to the continuous supervision of interviewers by a field manager, a sample of the first interviews was observed by Professor Clive Nancarrow. This permitted useful 
feedback on how best to handle the questionnaire for the rest of the team. (Interviews were conducted with managers and directors who may have a relatively 'rosy' picture as to how well customer retention is implemented within their own organisation. When asking about the customer management process, interviewers were allowed to accept practices even if they only applied to certain (key) customers. Therefore the survey probably shows an optimum state of the art. This should be borne in mind when looking at the overall results achieved.)

At the analysis stage the data were weighted in order to bring the sample into line with the business universe in terms of number of employees and service versus manufacturing sectors. The number of interviews achieved and the weighting used is as follows.

\section{FINDINGS}

\section{Importance of retention}

To establish which organisations were retention focused respondents were asked to allocate ten points between customer acquisition and retention, reflecting the weight they put on each. Over half of the sample (54 per cent) considered customer retention to be more important than acquiring new customers. Only 12 per cent rated customer acquisition above retention. Retention was particularly important to larger companies, those involved in mail order and those marketing to business customers rather than consumers.

Interestingly, a similarly high proportion of dot.coms also focused on retention (the median business life of the sample of dot.coms was one year).

Perhaps it is not surprising that retention focuses strongly in the minds of dot.coms given the example set by Amazon. It has been observed that 'the success of online marketer Amazon.com can be traced to its emphasis on three all-important business elements': ${ }^{15}$

- loyalty (the customer side of retention)

- quality

— dependability.

\section{Definition of customer retention}

Respondents were asked if their organisation or sphere of operation had an agreed definition of what constitutes customer retention, and if so, what this definition was. Interviewers were instructed to encourage the respondents to state the definition 'as fully as possible'. Only a quarter of the sample claimed that the company had a definition as to what constituted customer retention. The more likely to say this were larger organisations (39 per cent), those with larger databases (39 per cent), mail order companies (38 per cent) and dot.coms (40 per cent). At the same time, 20 per cent of those with a claimed definition, stated that they did not know what it was. Among those who knew, the majority gave behavioural definitions. The results are summarised in Table 3.

\section{Measurement of customer retention}

Although relatively few respondents claimed to have an agreed definition of customer retention, 58 per cent stated

Table 3: Definitions of customer retention

\begin{tabular}{lr} 
Keeping customers & $23 \%$ \\
Repeat/renew & $11 \%$ \\
Response to activity & $6 \%$ \\
$\ldots$ rather than attitudinal ones such as: & $17 \%$ \\
Satisfaction & \\
\hline
\end{tabular}


Table 4: Methods of measuring customer retention

\begin{tabular}{ll}
\hline & \% \\
Behaviour & $\mathbf{( 8 0 )}$ \\
\hline Trends in sales etc. & 34 \\
Sales (unspecified) & 6 \\
Sales at individual level & 12 \\
Percentage of customers buying & 15 \\
Bought in last period (recency) & 5 \\
Frequency & 3 \\
Attitude & $\mathbf{( 1 2 )}$ \\
Measure of declared loyalty/ & 2 \\
$\quad$ commitment & \\
Customer attitude & 8 \\
Product preference & 1 \\
\hline
\end{tabular}

(All claiming to measure -180 )

that their organisation measured customer retention. The larger the organisation and the bigger the database, the more likely they were to measure retention. Just over three-quarters of mail order companies (76 per cent) claimed to measure retention. Dot.coms were the least likely to measure retention.

Interviewers then probed the nature of measures used and were instructed to seek precise definitions. Examples were given at the briefing as well as for the analysts coding the answers. Once again, behavioural rather than attitudinal measures were more frequently used. Many of the measures were basic rather than sophisticated ( $\mathrm{cf}$ the possibilities listed earlier). The results are summarised in Table 4.

\section{Benchmarking customer retention levels}

Among those measuring retention, 38 per cent either did not have a benchmark against which to measure customer retention or did not know what benchmark (if any) was used. The main criterion against which retention was measured was a comparison with past performance (an introverted perspective). Only a few compared performance with competitors (external
Table 5: Benchmarks used to evaluate customer retention

\begin{tabular}{ll}
\hline & (\%) \\
\hline Comparison with past performance & 27 \\
Arbitrary target set by ourselves & 14 \\
Level of sales & 14 \\
Comparison with key competitors & 7 \\
Comparison with best available & 4 \\
Against national quality standards & 5 \\
Other & 14 \\
None & 15 \\
Don't know & 23 \\
\hline
\end{tabular}

Base: all measuring customer retention (180)

perspective). Other external benchmarks appeared to be more challenging such as 'comparison with the best' or 'against national quality standards'. The results are summarised in Table 5 .

\section{How well organisations use customer retention information}

Among those claiming to measure customer retention, almost three in five (58 per cent) stated that their senior management regularly monitored retention levels and a further 23 per cent stated that management monitored them occasionally. Fourteen per cent claimed senior management did not monitor customer retention levels. Those most likely to monitor retention levels tended to be in larger organisations, in those organisations with a definition of customer retention and, in particular, in mail order companies. Sixty-one per cent of those who measure customer retention claimed their organisation had a process whereby it ensured that retention measures actually have an impact on their business. These tend to be the same company types as those who monitor customer retention levels.

\section{Other customer information from database}

The survey was also designed to establish the types of information made available 
Table 6: Trends regularly available from the database

\begin{tabular}{ll}
\hline Total sample (\%) & Subgroups above the norm (\%) \\
\hline Frequency of customer purchase (61) & Larger companies (68), mail order (68) \\
Number of customers (58) & Larger companies (63), mail order (68), those with \\
Customer complaints (52) & $10,000+$ on database (66) \\
Customer retention (47) & Manufacturers (64) \\
Length of time have retained customers (47) & Mail order (70), charities (60) \\
Customer satisfaction levels (42) & Mail order (51), charities (66) \\
Customer loyalty levels (39) & Dot.coms (53) \\
Customer defection levels (30) & Mail order (65), charities (49) \\
Predicted customer defection levels (15) & Mail order (49) \\
& Mail order (30) \\
\hline
\end{tabular}

on a regular basis from customer databases to help put the internal distribution of retention measures into context. Trend data that were made regularly available from the customer database covered a variety of customer-related issues but mainly concerned:

- frequency of customer purchase (61 per cent)

- number of customers (58 per cent)

- customer complaints (52 per cent).

Customer defection levels (both actual and predicted) were the least likely trends to be drawn from the database. The results are summarised in Table 6 .

Interestingly, between 10 per cent and 15 per cent of those focused on retention thought the individual measures above were 'not relevant' or of 'no value'. One wonders about the logic of this. Perhaps, in a few cases, it simply reflects scepticism about the quality of data collection and research in general.

In an attempt to determine how sophisticated the analyses of database data on customers might be, respondents were presented with a prompt list of analyses. The results indicated considerable scope for more sophisticated and potentially useful analyses.

Overall, in the organisations interviewed, the customer database was broken down principally by the status of customers (71 per cent mentioning whether customer was new, current or lost) and type of product bought (63 per cent). In detail, the findings here were as follows:

- the most likely company types to organise databases by customer status were mail order companies (89 per cent), dot.coms (77 per cent), those marketing to individuals (79 per cent), and those with $10,000+$ on their database

- larger organisations and service-orientated companies were most likely to organise by product/service bought

- almost three quarters (73 per cent) of those with a $10,000+$ customer base organised by product/service bought

- customer spend (mentioned by 57 per cent in total) was most likely to be used by mail order companies (81 per cent), and those with a $10,000+$ database (69 per cent)

- customer profitability, current and forecast, was mentioned by 39 per cent and 32 per cent respectively

- current profitability was most likely to be mentioned by large companies (45 per cent), mail order and dot.coms (54 per cent and 60 per cent respectively)

- breakdown of customer database by 
forecast customer profitability was most likely to be mentioned by mail order and dotcoms (38 per cent and 44 per cent respectively).

Of course some organisations may market to customers who all spend a similar amount and are equally demanding in terms of cost-to-serve. This, however, seems likely to be a minority of organisations. The implication is that in the absence of this type of analysis, resources are unlikely to be distributed efficiently in many organisations.

Respondents were read out a list of information about named customers that might be collected by an organisation. They were asked which, if any, were made available to staff who communicate with customers either on an individual basis (sales representatives or service personnel for instance) or en masse (for direct marketing segmentation strategies, eg customer life cycle stages).

Nearly three-quarters (74 per cent) claimed to pass on the identity of customers who have complained - this was higher among small and medium-size companies (91 per cent) and dot.coms (88 per cent). The results are summarised in Table 7.

It will be noted that the figures in Table 7 are higher than in Table 6. This is because the question in Table 6 talked about trend data being made available regularly, while in Table 7 it is known from respondent feedback that the practice of making information available to staff in contact with customers includes respondents who may do it less than regularly.

\section{The special case of cross-selling}

One obvious way of using customer information is to look for cross-selling opportunities. Loyal customers, it is
Table 7: Information made available to staff in contact with customers

\begin{tabular}{lc}
\hline & $\%$ \\
\hline Identity of customers who ... & 74 \\
Have complained & 67 \\
Are not satisfied & 46 \\
Are likely to be lost (based on past & \\
$\quad$ experience) & 45 \\
Are not spending as much as expected & 45 \\
Whose purchase pattern has changed & \\
And & 60 \\
Important dates for customers & 60 \\
Competitor activity & 7 \\
None of these & \\
\hline
\end{tabular}

Base: all respondents

argued, buy a cross-section of products or services from an organisation. ${ }^{16}$ This has double significance as it not only provides additional income but can be one way of retaining customers (by increasing dependency on a supplier). The latter argument was examined in an attempt to gauge how credible this retention strategy was and whether it was ever tested in practice.

There was overwhelming agreement with the statement 'encouraging customers to buy other products helps your business retain customers' - 67 per cent agreed strongly with a further 17 per cent agreeing slightly. The level of agreement was highest among service organisations and those who market to both business and private individuals.

The basis behind the strength of agreement tended to be based on judgment (52 per cent) rather than hard evidence ( 47 per cent). The most likely company types to claim to have hard evidence to back up their reaction to cross selling were mail order and dot.com firms.

\section{CONCLUSIONS}

This paper shows that despite the enormous attention that has been paid to customer retention in the academic and 
management press and elsewhere, much is lacking in practice. In particular, many companies that claim to consider customer retention as an important business objective do not define it well or measure it. On this basis, companies' claims to focus on customer retention need to be treated with a pinch of salt. Companies that are serious about needing to improve customer retention should first define it clearly (and most companies may need several definitions of the term), and put in place operational measures that tell them clearly whether they are achieving improvements in it.

\section{References}

1 Stone, M. (1999) 'Managing good and bad customers, Part 1', Journal of Database Marketing, Vol. 6, No. 3, pp. 222-232 and Part 2, Journal of Database Marketing, Vol. 6, No. 4, pp. 299-314.

2 Wright, L. T. and Nancarrow, C. (1999) 'Researching international brand equity: A case study', International Marketing Review, Vol. 16, No. 4/5, pp. 417-431.

3 Backett, J. and Braverman, D. (1998) 'Backing the winners: The importance of understanding brand equity', Market Research Society Conference Proceedings, pp. 195-205.
4 Morgan, R. P. (2000) 'A consumer-orientated framework of brand equity and loyalty', International Journal of Market Research, Vol. 42, Issue 1, pp. 65-78.

5 Wright and Nancarrow (1999) op cit.

6 Kangis, P. and Zhang, Yangwei (2000) 'Service quality and customer retention in financial services', Journal of Financial Services Marketing, Vol. 4, No. 4, pp. 306-318.

7 Styan, G. P. H. and Smith, H. (1964) 'Markov chains applied to marketing', Journal of Marketing Research, February, pp. 50-54.

8 Backman, S. (1988) 'The utility of selected personal and marketing characteristics in explaining consumer loyalty to selected recreation services', Texas A \& M, USA.

9 Stratigos, A. (1999) 'Measuring end-user loyalty matters', onlinemag, Nov-Dec, p. 74.

10 Kangis, (2000) op. cit.

11 Liddy, A. (2000) 'Relationship marketing, loyalty programmes and the measurement of loyalty', Journal of Targeting, Measurement \& Analysis, Vol. 8, No. 4, pp. 351-362.

12 KPMG (1998) on www.kmpgconsulting/solutions.

13 Starkey, M., Stone, M. and Woodcock, N. (2000) 'The customer management scorecard', Business Intelligence.

14 Stone, M. and Woods, A. (2000) 'Making sense of cross-purchasing: A note', Journal of Financial Services Marketing, Vol. 5, No. 2, pp. 129-134.

15 Margolis, B. (1999) 'An Amazon.com story: Lessons learned?', Direct Marketing, Vol. 62, No. 3, p. 57

16 Griffin, J. (1996) 'The Internet's expanding role in building customer loyalty', Direct Marketing, Vol. 59, No. 7 , p. 50 . 